\title{
Defensive Medicine in the Emergency Department: ACross-sectional Study from the Perspective of Emergency Medical Specialists
}

\author{
(D) Orhan Delice1, (1) Erdal Tekin², (1) Sinan Yılmaz ${ }^{3}$
}

${ }^{1}$ Clinic of Emergency Medicine, University of Health Sciences, Erzurum Regional Training and Research Hospital, Erzurum, Turkey 2Department of Emergency Medicine, Atatürk University Faculty of Medicine, Erzurum, Turkey

${ }^{3}$ Department of Public Health, Atatürk University Faculty of Medicine, Erzurum, Turkey

\begin{abstract}
Aim: An increase in defensive medicine has recently been observed due to malpractice suits brought against physicians. This results in increased medical costs, requests for unnecessary tests, or delays in the treatment of high-risk patients.

Materials and Methods: Data were collected using an electronic questionnaire prepared by the authors following a review of the literature and sent to participants via docs.google.com. Numerical data were expressed as mean plus standard deviation, and categorical data as number and percentage. The Mann-Whitney $\mathrm{U}$ and Kruskal-Wallis tests were employed for data analysis.

Results: Men represented $67.9 \%(n=218)$ of the participants, and $70.7 \%(n=227)$ of our subjects were aged 24-35. In addition, $92.2 \%$ of participants considered that both consultant physicians in emergency departments (ED) and emergency physicians tended to be defensive in their approach to patients. Our findings showed that $88.1 \%(n=283)$ of participants requested more tests and consultations from patients arriving at the ED in order to avoid malpractice suits. Finally, 39.6\% $(n=127)$ of participants considered that emergency medicine specialists sought to avoid caring for complicated patients involving a greater workload in terms of tests, consultation, ED stay, and treatment.

Conclusion: Defensive medicine is a growing global phenomenon. The most undesirable and dangerous aspect of defensive medicine is that it also impacts on ED patients. The practice of ascribing every adverse patient outcome to the physician must be abandoned, and steps must be taken toward finding a solution.
\end{abstract}

Keywords: Defensive medicine, emergency department, malpractice, medical insurance

\section{Introduction}

Defensive medicine is defined as "physicians requesting additional tests in the absence of indications or else avoiding high-risk patient groups in which adverse outcomes may occur during diagnosis and treatment" $(1,2)$.

There are two forms of defensive medicine, namely positive and negative. Positive defensive medicine involves more procedures of no or little benefit to the patient's medical status (imaging, additional tests, and consultations) being requested than are required. Negative defensive medicine is defined as the avoidance of procedures in high-risk patients in terms of survival or complications (2-5).

An increase in defensive medicine has recently been seen due to malpractice suits brought against physicians. The disproportion between physicians' earnings and compensation payments deriving from such suits inevitably harms attitudes toward patients, and this results in increased medical costs, requests for unnecessary tests, or delays in the treatment of high-risk patients (6). Defensive medicine reduces the quality of health services and leads to distrust and dissatisfaction among patients. The consequences of defensive medicine also violate patients' rights 
and medical ethics $(2,7)$. By behaving defensively, physicians are, in effect, ignoring their legal responsibilities. Defensive medicine, encountered in almost all areas of health services, has also begun to impact on emergency department (ED) patients. Delayed admission due to consulting physicians requesting more tests and unnecessary consultations for high-risk patients in terms of survival presenting to the ED can also be included within the concept of defensive medicine (8). Having advanced tests that are non-urgent and can easily be performed after admission carried out in the ED instead can lead to delayed admission, unnecessary occupation of the ED, resource wastage, and increased morbidity and mortality.

This study investigated the defensive medicine applied to ED patients by emergency medicine specialists/residents and consultant physicians (from other departments).

\section{Materials and Methods}

\section{Study Design}

The requisite ethical committee approvals were granted for this cross-sectional study (protocol no.: BEAH KAEK 2019/11-119). Data were collected using an electronic questionnaire prepared by the authors following a review of the literature and sent to participants via docs.google.com. This questionnaire consisted of questions/propositions concerning demographic data, professional experience, a region of employment, number of patients served, and the perceptions and opinions of physicians working in the area regarding defensive medicine. Questions regarding defensive medicine were 5-point Likert type, with responses closer to 5 expressing more significant disagreement with the presence of defensive medicine. Our aim in this study was to evaluate consultant physicians' attitudes toward patients in the ED through the eyes of emergency medicine specialists/ residents and to investigate tendencies to adopt defensive medicine.

\section{Participant Selection}

Three hundred and sixty-nine out of 500 emergency medicine specialists and specialist students who work in our country and whose contact information can be accessed have agreed to participate in the study. The data collection process lasted six months, at the end of which 48 questionnaires were discarded for being incomplete or carelessly completed (Figure 1). The participation rate was $86.9 \%$.

\section{Data Analysis}

Data analysis was performed on Statistical Package for the Social Sciences version 22 software. Numerical data were expressed as mean plus standard deviation, and categorical data as number and percentage. Compatibility with normal distribution was assessed using the Kolmogorov-Smirnov test. The MannWhitney $\mathrm{U}$ and Kruskal-Wallis tests were used in the analysis of non-normally distributed numerical data. P values $<0.05$ were regarded as statistically significant.

\section{Results}

Men represented $67.9 \%(n=218)$ of the participants, and $70.7 \%$ $(n=227)$ of subjects were aged 24-35. Physicians with 1-10 years' work experience constituted $86.9 \%(n=279)$ of the participants, and $53.0 \%(n=170)$ served $300-600$ patients over a $24-h$ period. The highest level of participation was from the Eastern Anatolia region of Turkey, at $22.4 \%(n=72)$. Various sociodemographic characteristics of the participants are shown in Table 1.

We observed that $92.2 \%$ of participants considered that both consultant physicians in EDs and emergency physicians tended to exhibit defensive medicine. Emergency and consultant physicians' defensive tendencies were unaffected by variables such as age, gender, length of time in the profession, numbers of patients served in $24 \mathrm{~h}$, and region of employment.

Seventy-one percent of participants $(n=228)$ thought that the use of imaging techniques had increased following the

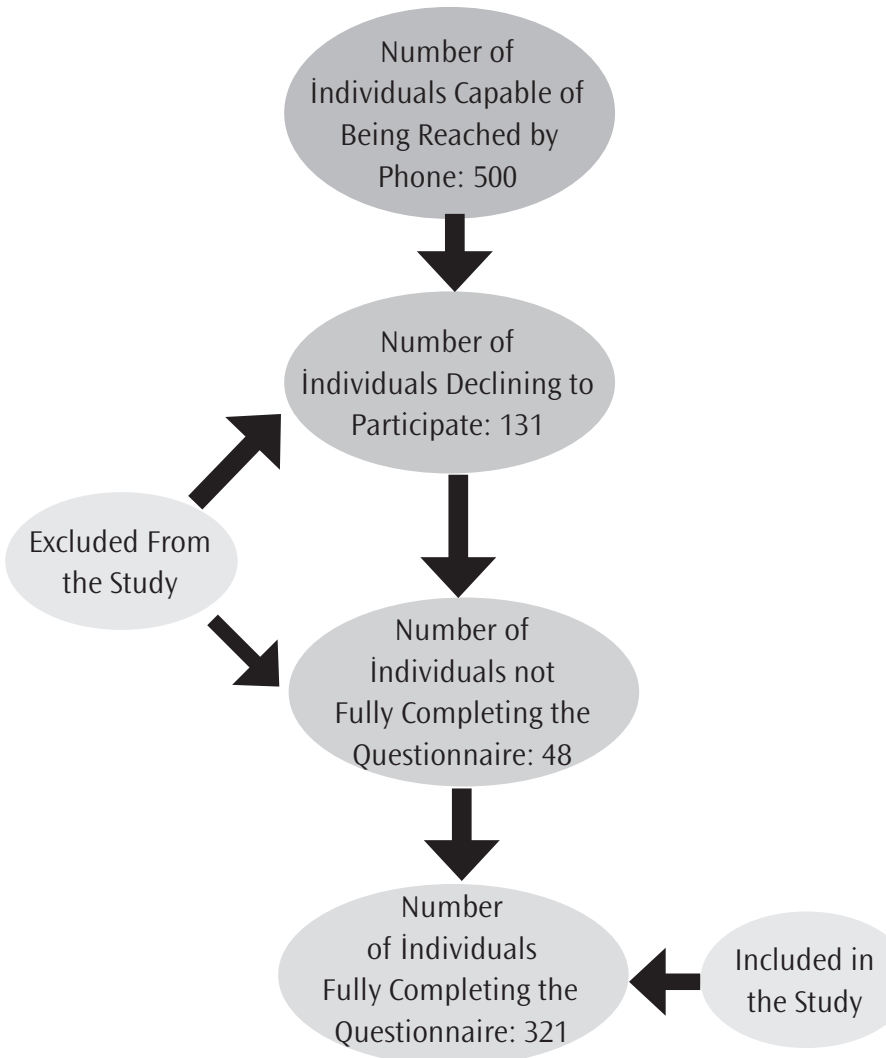

Figure 1. Flowchart: Number of people included and not included in the study 
introduction of compulsory financial liability insurance against medical malpractice. Additionally, $93.1 \%$ of participants $(n=299)$ reported that the use of computed tomography had increased. Moreover, $88.1 \%$ of participants $(n=283)$ requested more tests

Table 1. Participants' sociodemographic characteristics

\begin{tabular}{|c|c|c|}
\hline Characteristics & Number & Percentage \\
\hline \multicolumn{3}{|l|}{ Age } \\
\hline $24-35$ years & 227 & 70.7 \\
\hline $36-45$ years & 78 & 24.3 \\
\hline$\geq 46$ years & 16 & 5.0 \\
\hline \multicolumn{3}{|l|}{ Gender } \\
\hline Male & 218 & 67.9 \\
\hline Female & 103 & 32.1 \\
\hline \multicolumn{3}{|l|}{ Length of service } \\
\hline $1-10$ years & 279 & 86.9 \\
\hline $11-20$ years & 28 & 8.7 \\
\hline$>20$ years & 14 & 4.4 \\
\hline \multicolumn{3}{|c|}{$\begin{array}{l}\text { Number of patients served in } \\
24 \mathrm{~h}\end{array}$} \\
\hline $300-600$ & 170 & 53.0 \\
\hline $601-1000$ & 106 & 33.0 \\
\hline$>1000$ & 45 & 14.0 \\
\hline \multicolumn{3}{|c|}{ Region where employed } \\
\hline Eastern Anatolia & 72 & \\
\hline Mediterranean & 21 & $\begin{array}{ll}2 Z .4 \\
6.5\end{array}$ \\
\hline Aegean Coast & 53 & 6.5 \\
\hline Southeast Anatolia & 21 & 16.5 \\
\hline Central Anatolia & 62 & $\begin{array}{l}6.519 .3 \\
140 .\end{array}$ \\
\hline Black Sea & 45 & 14.0 \\
\hline Marmara & 47 & 14.0 \\
\hline
\end{tabular}

and consultations for patients presenting to the ED in order to avoid malpractice suits in such departments (Table 2).

Ninety-five percent of participants $(n=305)$ thought that consultant physicians in the ED exhibited reluctance by requesting unnecessary tests and consultations. Also, 87.6\% $(n=282)$ of participants thought that clinicians were reluctant to admit patients, even when this was indicated. Moreover, 90.3\% $(n=290)$ of participants considered that consultant physicians were reluctant to admit patients in generally poor condition, while $95.3 \%$ ( $n=306)$ thought that they preferred to complete unnecessary tests and consultations in the ED (Table 3).

In our study, $85.9 \%$ of participants ( $\mathrm{n}=276$ ) thought that internal medicine clinics exhibited the most considerable reluctance concerning consultation and admittance procedures for ED patients, and $82.8 \%(n=266)$ considered that the hospital administration was passive in intervening (Table 4).

We observed that $39.6 \%(n=127)$ emergency medicine specialists considered that there was a reluctance to care for complicated cases involving a higher workload in terms of tests, consultation, length of stay in the ED, and treatment. Also, $88.1 \%(n=283)$ of participants thought that more tests and consultations tended to be requested for ED patients (Table 5).

Seventy-six percent of respondents $(n=244)$ reported that clinics from which they requested consultations referred patients to other clinics without seeing them, while $80.7 \%(n=259)$ reported that clinics behaved as if consultations requests were unnecessary in the case of patients whom they did see. Additionally, 55.8\%

Table 2. Emergency department physicians' opinions concerning test requests for patients

\begin{tabular}{|c|c|c|c|}
\hline Question/Proposition & Responses & Percentage & Number \\
\hline \multirow{5}{*}{$\begin{array}{l}\text { The frequency of the use of imaging techniques (USG, MRI, and CT) during the } \\
\text { diagnosis of patients in the ED was influenced by the introduction of medical } \\
\text { liability insurance. }\end{array}$} & Definitely agree & 36.4 & 117 \\
\hline & Agree & 34.6 & 111 \\
\hline & Unsure & 11.8 & 38 \\
\hline & Disagree & 13.1 & 42 \\
\hline & Definitely disagree & 4.0 & 13 \\
\hline \multirow{4}{*}{$\begin{array}{l}\text { If you think the use of imaging has increased, which technique has seen the } \\
\text { most significant increase? }\end{array}$} & USG & 4.4 & 14 \\
\hline & MRI & 1.6 & 5 \\
\hline & $\mathrm{CT}$ & 93.1 & 299 \\
\hline & X-ray & 0.9 & 3 \\
\hline \multirow{5}{*}{$\begin{array}{l}\text { More tests and consultations are being requested in order to avoid malpractice } \\
\text { suits in the ED. }\end{array}$} & Definitely agree & 43.9 & 141 \\
\hline & Agree & 44.2 & 142 \\
\hline & Unsure & 4.4 & 14 \\
\hline & Disagree & 6.9 & 22 \\
\hline & Definitely disagree & 0.6 & 2 \\
\hline
\end{tabular}


$(n=179)$ of ED physicians considered that surgical clinics encouraged patients or families not to undergo surgery by providing misleading or dissuasive information, while $64.8 \%$
( $n=208)$ considered that aggressive or complaining behavior by patients and/or families affected consultant physicians' attitudes toward patients (Table 6).

Table 3. Emergency physicians' opinions concerning the attitudes of consultant physicians to patients requiring consultation and hospitalization

\section{Question/Proposition}

The clinicians you invite to the ED are reluctant to admit patients by requesting unnecessary tests or consultations.

The clinician concerned is generally reluctant to admit even if the patient you evaluate in the ED has admission indication.

The clinic exhibits reluctance during the admission of patients in generally poor condition from your ED.

Other consultations and tests are performed in the ED for patients due to be admitted to other departments.

The relevant clinic physician does not seek space for a patient considered for admission to that department from the ED. The search for space is generally left to emergency physicians.

ED: Emergency department

\begin{tabular}{lll} 
Response & Number & Percentage \\
\hline Definitely agree & 199 & 62.0 \\
\hline Agree & 106 & 33.0 \\
\hline Unsure & 8 & 2.5 \\
\hline Disagree & 7 & 2.2 \\
\hline Definitely disagree & 1 & 0.3 \\
\hline Definitely agree & 140 & 43.6 \\
\hline Agree & 142 & 44.2 \\
\hline Unsure & 19 & 5.9 \\
\hline Disagree & 20 & 6.2 \\
\hline Definitely disagree & - & - \\
\hline Definitely agree & 186 & 57.9 \\
\hline Agree & 104 & 32.4 \\
\hline Unsure & 22 & 6.9 \\
\hline Disagree & 8 & 2.5 \\
\hline Definitely disagree & 1 & 0.3 \\
\hline Definitely agree & 195 & 60.7 \\
\hline Agree & 111 & 34.6 \\
\hline Unsure & 1 & 0.3 \\
\hline Disagree & 12 & 3.7 \\
\hline Definitely disagree & 2 & 0.6 \\
\hline Definitely agree & 220 & 68.5 \\
\hline Agree & 74 & 3.7 \\
\hline Unsure & 12 & 0.3 \\
\hline Disagree & 14 & \\
\hline Definitely disagree & 1 & \\
\hline & & \\
\hline
\end{tabular}

Table 4. Emergency department physicians' opinions concerning other clinics and hospital administrations

\begin{tabular}{|c|c|c|c|}
\hline Question/Proposition & Response & Number & Percentage \\
\hline \multirow{4}{*}{$\begin{array}{l}\text { Internal medicine clinics exhibit greater reluctance in terms of consultations } \\
\text { in the ED and of admission. }\end{array}$} & Definitely agree & 177 & 55.1 \\
\hline & Agree & 99 & 30.8 \\
\hline & Disagree & 10 & 3.1 \\
\hline & Definitely disagree & 1 & 0.3 \\
\hline & Agree & 107 & 33.3 \\
\hline $\begin{array}{l}\text { The hospital administration is passive toward clinics that are reluctant in terms of } \\
\text { consultation and admission. }\end{array}$ & Unsure & 24 & 7.5 \\
\hline & Disagree & 27 & 8.4 \\
\hline & Definitely disagree & 4 & 1.2 \\
\hline
\end{tabular}


Table 5. Emergency department physicians' regarding consultation procedures for complicated patients

Question/Proposition
Some emergency specialists in the ED avoid caring for complicated patients
(a patient group involving a greater workload).
(a patient group involving a greater workload).

Excessive tests and consultations are requested in the ED in order to avoid malpractice suits.

Procedures in the ED, such as requesting consultations, admitting patients, and seeking places for patients adversely impact on the time you spend on the telephone, taking histories, and physical examinations.

You have to convince the consultant physician from the clinic from which consultation is requested to take care of the patient.

\begin{tabular}{lll} 
Response & Number & Percentage \\
\hline Definitely agree & 59 & 18.4 \\
\hline Agree & 68 & 21.2 \\
\hline Unsure & 52 & 16.2 \\
\hline Disagree & 109 & 34.0 \\
\hline Definitely disagree & 33 & 10.3 \\
\hline Definitely agree & 141 & 43.9 \\
\hline Agree & 142 & 44.2 \\
\hline Unsure & 14 & 4.4 \\
\hline Disagree & 22 & 6.9 \\
\hline Definitely disagree & 2 & 0.6 \\
\hline Definitely agree & 223 & 69.5 \\
\hline Agree & 87 & 27.1 \\
\hline Unsure & 5 & 1.6 \\
\hline Disagree & 6 & 1.9 \\
\hline Definitely disagree & - & - \\
\hline Definitely agree & 127 & 39.6 \\
\hline Agree & 112 & 34.9 \\
\hline Unsure & 36 & 11.2 \\
\hline Disagree & 39 & 12.1 \\
\hline Definitely disagree & 7 & 2.2 \\
\hline & & \\
\hline & & \\
\hline
\end{tabular}

ED: Emergency department

Table 6. Emergency health professionals' opinions concerning consultant physicians' attitudes toward emergency patients

\begin{tabular}{|c|c|c|c|}
\hline Question/Proposition & Response & Number & Percentage \\
\hline \multirow{5}{*}{$\begin{array}{l}\text { The physician from whom you request a consultation generally suggests that } \\
\text { another clinic or clinics examine the patient, after which the physician will do so, } \\
\text { before even seeing the patient. }\end{array}$} & Definitely agree & 105 & 32.7 \\
\hline & Agree & 139 & 43.3 \\
\hline & Unsure & 45 & 14.0 \\
\hline & Disagree & 29 & 9.0 \\
\hline & Definitely disagree & 3 & 0.9 \\
\hline \multirow{5}{*}{$\begin{array}{l}\text { When the ED requests a consultation, we generally hear discouraging comments } \\
\text { from the consultant, such as 'Why did you bother me with this? This has nothing to } \\
\text { do with me. I have written a note on the file'. }\end{array}$} & Definitely agree & 122 & 38.0 \\
\hline & Agree & 137 & 42.7 \\
\hline & Unsure & 40 & 12.5 \\
\hline & Disagree & 21 & 6.5 \\
\hline & Definitely disagree & 1 & 0.3 \\
\hline \multirow{5}{*}{$\begin{array}{l}\text { A surgeon who is reluctant to intervene encourages the patient/family to refuse } \\
\text { surgery by providing misleading or dissuasive information. }\end{array}$} & Definitely agree & 74 & 23.1 \\
\hline & Agree & 105 & 32.7 \\
\hline & Unsure & 82 & 25.5 \\
\hline & Disagree & 55 & 17.1 \\
\hline & Definitely disagree & 5 & 1,6 \\
\hline \multirow{5}{*}{$\begin{array}{l}\text { Aggressive behavior and complaints from patients and relatives in the ED make } \\
\text { consultant physicians reluctant to care for and admit patients. }\end{array}$} & Definitely agree & 79 & 24.6 \\
\hline & Agree & 129 & 40.2 \\
\hline & Unsure & 73 & 22.7 \\
\hline & Disagree & 36 & 11.2 \\
\hline & Definitely disagree & 4 & 1.2 \\
\hline
\end{tabular}

ED: Emergency department 


\section{Discussion}

All health workers, and particularly physicians, have employed defensive methods with which to protect themselves while engaged in their profession, based on the conditions applying at the time. Unfortunately, defensive medicine can lead to positive or negative practices by distracting practitioners away from evidence-based medicine (9). Negative defensive medicine practices include concealing or not employing high-risk therapies and diagnostic tests in order to avoid potential risks in patient care and resulting claims of malpractice (5). Positive defensive medicine involves unnecessary and excessive use of diagnostic tests and interventions by health service providers in order to minimize risks that may be encountered in health care (5). In a study of 824 specialist physicians in high-risk departments in Pennsylvania, Studdert et al. (10) reported that 93\% of participants employed defensive medicine, while in their study of medical students, Rodriguez et al. (11) reported an increase in concerns over malpractice and defensive thinking as students approached graduation. In our study, $92.2 \%$ of participants considered that both consultants and emergency physicians employed defensive medicine. In their study of brain surgeons, Solaroglu et al. (12) determined that $82.4 \%$ of subjects tended to employ defensive medicine and that they were affected by sociodemographic characteristics such as age, geographical region of residence, and region of employment. In our study, however, emergency medicine specialists' dispositions to defensive medicine were unaffected by sociodemographic characteristics. We attribute the discrepancy between Solaroglu et al.'s (12) study and our own to the different specialty fields involved. Nahed et al. (13) reported that $72 \%$ of participants employed more imaging techniques due to a fear of malpractice claims (13). In this study, it was found that imaging methods increased in ED.

Although malpractice is a matter of anxiety to all health workers, it primarily concerns physicians, as being solely responsible for the patient, and leads to an increase in unnecessary consultation and test requests. These unnecessary procedures slow down health services, lower their quality, and lead to increased costs (14). Wong et al. (15) reported that due to concerns over malpractice, emergency physicians requested computed tomography for child patients even with only minor head traumas (15). In this study, tended to request more examination and consultation because of the malpractice anxiety of the emergency service workers. They may make considerable efforts to avoid even complicated patients in the poor general condition being admitted to their clinics. This defensive approach leads to loss of time and increased costs as a result of which the patient may also suffer harm $(6,16,17)$. In a study involving radiation oncologists, Ramella et al. (18) reported that due to concerns over malpractice, $43 \%$ of participants shared documentation regarding diagnosis and treatment with colleagues and requested their opinions (18). In our study, the participants thought that the consultant physicians applied for defensive medicine by requesting unnecessary investigations and consultations from the patients in the ED.

EDs are units that operate on the $24 / 7$ principle and where procedures are performed very quickly. Also, due to increasing patient crowding, great efforts are made to accelerate procedures in EDs still further. Both patients and families and also consultant physicians frequently take advantage of this feature of EDs. In our study, $95.3 \%$ of participants considered that consultant physicians take advantage of the rapid functioning of EDs. Also, in this chaotic environment, the task of finding space for patients admitted to clinics is left to emergency physicians. In our study, 91.6\% of participants reported that physicians applying defensive medicine to patients in the ED also expected emergency physicians to undertake the task of finding space for them.

EDs are units that represent the first point of presentation for high-risk patients and that exhibit high patient turnover. ED physicians may, therefore, request more tests than necessary and seek to share risks with other clinics (19). In addition to the high density of risky patients in EDs and the stress in the working environment, emergency physicians also experience problems with professional colleagues; much time is lost due to procedures such as requesting consultations by telephone and convincing colleagues to perform them and admission or referral procedures. In our study, most participants reported being unable to devote sufficient time to patients due to unnecessary tasks and procedures in the ED.

Similarly to physicians from other branches, there is also a tendency to employ positive and negative medicine among ED physicians (6). The tendency in emergency physicians generally manifests in the form of requesting unnecessary tests and consultations. Katz et al. (20) investigated the attitudes of physicians to patients with chest pains in the ED from the perspective of malpractice fears. They observed that physicians requested more tests and consultation than necessary in order not to overlook medical conditions, and that they even admitted patients with low-risk chest pains (20). Similarly, in the present study, requested unnecessary tests and consultations due to concerns over malpractice suits.

Despite the high tendency to defensive medicine, emergency physicians still have an obligation to care for risky and complicated patients. Although specialists from other branches also have such obligations, they may still sometimes avoid assuming responsibility for patients through various delaying tactics or by referring them directly to the ED. Consultant physicians invited 
to the ED sometimes request that other relevant clinics evaluate the patient and exhibit negative behaviors toward emergency physicians. In the present study, reported being subjected to reluctance or negative attitudes on the part of consultant physicians. Surgical departments may sometimes provide dissuasive or misleading information in order to persuade the patient or the family against surgery. We observed that considered that surgical clinics attempted to dissuade patients from surgery.

\section{Study Limitations}

There are several limitations to our study. First, the study data were collected using a questionnaire sent out electronically, rather than at face-to-face interviews. Also, participation in this study, which was planned on a nationwide basis, was low due to difficulties in obtaining up-to-date communication details for emergency medicine specialists and residents. Our study also involved only ED physicians and not specialists from other branches.

\section{Conclusion}

Defensive medicine is resulting in countries facing increased health spending, reduced patient satisfaction, and reduced quality of health services. This study shows that EDs are significantly affected by this medical malpractice situation. A malpractice law setting out the responsibilities of the patient, physician, and health administration must be established. EDs' working conditions and functioning must be reviewed. Public awareness activities aimed at preventing the use of EDs for other than their intended purposes and at increasing their efficiency are also needed.

\section{Ethics}

Ethics Committee Approval: The requisite ethical committee approvals were granted for this cross-sectional study (protocol no.: BEAH KAEK 2019/11-119).

Informed Consent: Consent form was filled out by all participants.

Peer-review: Externally and internally peer-reviewed.

\section{Authorship Contributions}

Surgical and Medical Practices: E.T., O.D., S.Y., Concept: E.T., O.D., S.Y., Design: E.T., O.D., S.Y., Data Collection or Processing: E.T., O.D., S.Y., Analysis or Interpretation: E.T., S.Y., Literature Search: O.D., S.Y., Writing: E.T., O.D., S.Y.

Conflict of Interest: No conflict of interest was declared by the authors.
Financial Disclosure: The authors declared that this study received no financial support.

\section{References}

1. Hermer L, Brody H. Defensive Medicine, Cost Containment and Reform. J Gen Intern Med. 2010;25:470-3.

2. Tuers DM. Defensive Medicine in the Emergency Department Increasing Health Care Costs Without Increasing Quality? Nurs Adm Q. 2013;37:160-4.

3. Johnston WF, Rodriguez RM, Suarez D, Fortman J. Study of Medical Students' Malpractice Fear and Defensive Medicine: A "Hidden Curriculum?". West J Emerg Med. 2014;15:293-8.

4. Waxman DA, Greenberg MD, Ridgely MS, Kellermann AL, Heaton P. The Effect of Malpractice Reform on Emergency Department Care. N Engl ] Med. 2014;371:1518-25

5. Summerton N. Positive and Negative Factors in Defensive Medicine: a Questionnaire Study of General Practitioners. BMJ. 1995 310:27-9.

6. Smith TR, Habib A, Rosenow JM, Nahed BV, Babu MA, Cybulski G, et al. Defensive Medicine in Neurosurgery: Does State-Level Liability Risk Matter? Neurosurgery. 2015;76:105-14.

7. Yılmaz K, Polat O, Kocamaz B. Investigation of Defensive Medicine Practice from the Legal Angle. TAAD. 2014;5:19-51.

8. Li S, Brantley E. Malpractice Liability Risk and Use of Diagnostic Imaging Services: A Systematic Review of the Literature. J Am Coll Radiol. 2015;12:1403-12.

9. Dirnhofer R, Wyler D. Treatment Failure From the Viewpoint of Forensic Medicine. Ther Umsch. 1997;54:272-9.

10. Studdert DM, Mello MM, Adaçayı WM, DesRoches CM, Peugh J, Zapert K, et al. Defensive Medicine Among High-Risk Specialist Physicians in a Volatile Malpractice Environment. JAMA. 2005;293:2609-17.

11. Rodriguez R, Anglin D, Hankin A, Hayden SR, Phelps M, McCollough L, et al. A Longitudinal Study of Emergency Medicine Residents' Malpractice Fear and Defensive Medicine. Acad Emerg Med. 2007;14:569-73.

12. Solaroglu I, Izci Y, Yeter HG, Metin MM, Keles GE. Health Transformation Project and Defensive Medicine Practice Among Neurosurgeons in Turkey. PLoS ONE. 2014;9:e111446.

13. Nahed BV, Babu MA, Smith TR, Heary RF. Malpractice Liability and Defensive Medicine: A National Survey of Neurosurgeons. PLoS One. 2012;7.

14. Büken NÖ, Büken E. Dıscussıons on Medıcal Malpractıces and Medıcal Ethıcs. T Klin J Med Ethics, Law and History. 2003;11:140-7.

15. Wong AC, Kowalenko T, Roahen-Harrison S, Smith B, Maio RF, Stanley RM. A Survey of Emergency Physicians' Fear of Malpractice and Its Association With the Decision to Order Computed Tomography Scans for Children With Minor Head Trauma. Pediatr Emerg Care. 2011;27:182-5.

16. Brennan T. Overview of Legal İssues. Jt Comm J Qual Improv. 1993;19:319-21

17. Moser JW, Applegate KE. Imaging and Insurance: Do the Uninsured Get Less Imaging in Emergency Departments? J Am Coll Radiol. 2012;9:50-7.

18. Ramella S, Mandoliti G, Trodella L, D'Angelillo RM. The First Survey on Defensive Medicine in Radiation Oncology. Radiol Med. 2015;120:421-9.

19. Cervellin G, Cavazza M. Defensive Medicine in the Emergency Department. The Clinicians' Perspective. Emergency Care Journal. 2016;12:5615.

20. Katz DA, Williams GC, Brown RL, Aufderheide TP, Bogner M, Rahko SP, et al. Emergency Physicians' Fear of Malpractice in Evaluating Patients with Possible Acute Cardiac Ischemia. Ann Emerg Med. 2005;46:525-33. 